
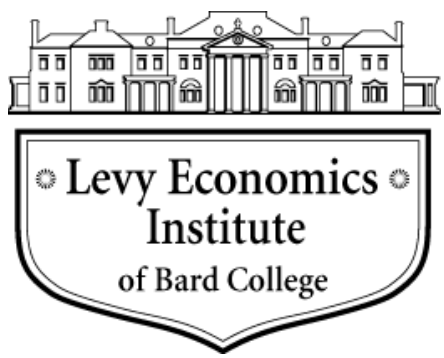

Working Paper No. 907

\title{
Some Comments on the Sraffian Supermultiplier Approach to Growth and Distribution
}

\section{Michalis Nikiforos*}

Levy Economics Institute of Bard College and

May 2018

* I am grateful to Sergio Cesaratto, Steve Fazzari, Marc Lavoie, Mark Setterfield, Peter Skott, and Luca Zamparelli for useful comments and suggestions. The usual disclaimer applies.

The Levy Economics Institute Working Paper Collection presents research in progress by Levy Institute scholars and conference participants. The purpose of the series is to disseminate ideas to and elicit comments from academics and professionals.

Levy Economics Institute of Bard College, founded in 1986, is a nonprofit, nonpartisan, independently funded research organization devoted to public service. Through scholarship and economic research it generates viable, effective public policy responses to important economic problems that profoundly affect the quality of life in the United States and abroad.

\author{
Levy Economics Institute \\ P.O. Box 5000 \\ Annandale-on-Hudson, NY 12504-5000 \\ http://www.levyinstitute.org
}

Copyright (C Levy Economics Institute 2018 All rights reserved

ISSN 1547-366X 


\begin{abstract}
The paper discusses the Sraffian supermultiplier (SSM) approach to growth and distribution. It makes five points. First, in the short run the role of autonomous expenditure can be appreciated within a standard post-Keynesian framework (Kaleckian, Kaldorian, Robinsonian, etc.). Second, and related to the first, the SSM model is a model of the long run and has to be evaluated as such. Third, in the long run, one way that capacity adjusts to demand is through an endogenous adjustment of the rate of utilization. Fourth, the SSM model is a peculiar way to reach what Garegnani called the "Second Keynesian Position.” Although it respects the letter of the "Keynesian hypothesis," it makes investment quasi-endogenous and subjects it to the growth of autonomous expenditure. Fifth, in the long run it is unlikely that "autonomous expenditure” is really autonomous. From a stock-flow consistent point of view, this implies unrealistic adjustments after periods of changes in stock-flow ratios. Moreover, if we were to take this kind of adjustment at face value, there would be no space for Minskyan financial cycles. This also creates serious problems for the empirical validation of the model.
\end{abstract}

KEYWORDS: Sraffian Supermultiplier; Long Run; Utilization; Autonomous Demand

JEL CLASSIFICATIONS: B22; B5; E12; E32; O4 


\section{INTRODUCTION}

The last years have witnessed a growing interest in the so-called Sraffian supermultiplier (SSM) model, introduced by Franklin Serrano (1995). It builds on the work and ideas of Pierangelo Garegnani $(1962,1992)$ and borrows features from the original supermultiplier model of John Hicks (1950). Recent contributions include Bortis (1997), Cesaratto, Serrano, and Stirati (2003), de-Juan (2005), Freitas and Serrano (2015), Cesaratto (2015), Serrano, Freitas, and Bhering (2017), Fazzari et al. (2013), and Fazzari, Ferri, and Variato (2018).

The model follows what Garegnani (1992) called the "Second Keynesian Position," that combines an autonomous role for aggregate demand together with a classical-Sraffian theory of distribution. At the same time, the system of the model converges toward an exogenous-todemand, "normal" degree of capacity utilization. For many, not only Sraffians, this is a desired feature of a growth model. For example, Committeri (1986), Auerbach and Skott (1988), Duménil and Lévy (1999), Shaikh (2009), and Skott $(2010,2012)$ have criticized the Kaleckian model on this basis. That is the reason why some Kaleckians (Allain 2015; Lavoie 2016) have recently integrated the SSM framework within a Kaleckian model, which then achieves the normal utilization rate and preserves the main conclusions of the canonical model, like the paradox of thrift and the paradox of costs as level effects.

Within the SSM model, in the long and medium run the system converges to a balanced growth path where everything — growth rate of output, rate of accumulation of capital, savings, etc.-is

driven by the growth rate of autonomous expenditure. Autonomous expenditure is defined as the expenditure that is independent of income and other economic variables. These categories of expenditure include autonomous consumption, residential investment, government expenditure, and exports. Changes in variables such as the saving rate, income distribution, and the propensity to invest have growth effects only temporarily. In the long run these effects fade away and remain only as level effects.

This present paper provides a critical discussion of the SSM model. I make five brief points. First, the positive effects of increases in autonomous expenditure on economic activity can be derived within any post-Keynesian model (Kaleckian, Kaldorian, Robinsonian, etc). Within a 
demand-led model, increases in autonomous demand always lead to increases in output—at least in the short run. Therefore, the short- and medium-run results of the SSM model are unoriginal.

Second, and related to that, the SSM model is thus a long-run model. Its main contribution is to provide a theory of long-run growth based on autonomous expenditure. Therefore, its assumptions and conclusions have to be evaluated with reference to the long run.

Third, in the long run part of the adjustment takes place through a change in the normal degree of capacity utilization. In two recent papers (Nikiforos 2013, 2016b) I have argued that an endogenous rate of capacity utilization is consistent with a firm that minimizes its cost and that empirical evidence confirms such an endogeneity. Therefore, the fully adjusted position of the system is endogenous to demand and the short-run growth effects carry over to the long run.

Fourth, the SSM model is a peculiar way to reach what Garegnani (1992) called the Second Keynesian Position, that is a combination of a demand-led model with a classical-Sraffian theory of distribution. Although investment is independent from savings, it does not really have an autonomous role, but it adjusts endogenously to the rate of growth of autonomous expenditure.

Finally, since we are dealing with a long-run model, we need to ask if the so-called “autonomous expenditure” is really autonomous in the long run. Can expenditure categorieslike residential investment, debt-financed consumption, or government expenditure-be independent from income in the long run? On first thought, this is not convincing. Do households make decisions about their residential investment expenditure without any reference to their expected lifecycle flow of income? Do governments draft their budget without reference to the expected rate of growth? Maybe sometimes in the short run, but in the long run? More fundamentally, I argue that stock-flow consistency requires that debt-financed autonomous expenditure leads to accumulation of debt. In the SSM model the related debt-to-income ratios converge to a constant value. But what happens when for some reason there is an increase in this debt-to-income ratio? The SSM model predicts that the growth rate would eventually accelerate to stabilize the debt-to-income ratios. However, according to the theory of financial 
instability and crises (Minsky 1975, 1986; Kindleberger and Aliber 2011), and as we have repeatedly seen in the last decades in several instances around the world, the main variable that adjusts is the "autonomous" expenditure. Households in the United States borrowed a lot to buy houses, their debt-to-income ratio increased, and this autonomous process drove the economy for a while - for a short to medium run — but eventually in the face of the increase in their debtto-income ratio, households had to decrease their residential investment expenditure. However, if adjustment takes place this way, then the so-called autonomous expenditure ceases to be autonomous in the long run. But if this is the case then the SSM model remains like a cart without its horse.

The paper proceeds as follows. Section 2 discusses the role of autonomous demand in the SSM model and in a standard post-Keynesian model and shows that the positive effects of autonomous demand can also be derived within the latter. In the same section I explain why the SSM is a model of the long run. Section 3 illustrates why the normal rate of utilization is endogenous in the long run and section 4 makes the point that the closure of the SSM model respects the letter but not the spirit of the Keynesian hypothesis. Section 5 argues that the socalled autonomous expenditure is not autonomous in the long run. Section 6 concludes.

\section{AUTONOMOUS EXPENDITURE IN A DEMAND-DRIVEN MODEL}

\subsection{The Short Run}

At the heart of the SSM model lies autonomous, non-capacity-generating spending. Autonomous means that is not affected by other economic variables within the system. ${ }^{1}$ These kinds of expenditures include debt-financed consumption, capitalist consumption, residential investment, government expenditure, and exports. Since the system, by assumption, converges to a balanced growth path with a normal rate of utilization, autonomous expenditure-whose growth is also assumed to be exogenous - sets the tone in the long run and the whole system grows at the rate of growth of the autonomous expenditure. Changes in autonomous spending are transmitted to output through the supermultiplier. Since the growth rate of output is pinned

\footnotetext{
${ }^{1}$ Skott $(2017,2)$ adds to this definition a second criterion that "its movements must not be offset automatically by changes in other components of demand.”
} 
down by the exogenous growth rate of autonomous spending, changes in other variables that usually have a more central role in demand-driven models (e.g., saving rate, income distribution) have only a transitory or level effect on economic activity (Freitas and Serrano 2015; Allain 2015; Lavoie 2016).

It is worth pointing out that if we consider a certain part of expenditure as autonomous, it is trivial to show that within a Keynesian model an increase in this autonomous expenditure will have a positive effect on economic activity. Take for example a standard Kaleckian model with the following investment and saving functions:

$$
\begin{gathered}
g^{i}=g^{i}\left[\gamma, \pi,\left(u-u_{d}\right)\right] \\
g^{s}=g^{s}\left(s_{\pi}, s_{\psi}, \pi, u\right)
\end{gathered}
$$

where $g^{i}$ and $g^{s}$ are investment and saving normalized to capital stock, $\gamma$ is a term that captures expectations about the growth rate, $\pi$ is the profit share, $u-u_{d}$ is the deviation of the actual from desired/normal rate of capacity utilization, and $s_{\pi}$ and $s_{\psi}$ are the saving rates of capitalists and workers, respectively. All partial derivatives are positive. We can also define the warranted growth rate $\left(\gamma_{w}\right)$, which is the growth rate where actual and normal utilization are equal. ${ }^{2}$

Assume an exogenous distribution of income and an also exogenous/autonomous component of demand $(z)$. It is not hard to show that the short-run equilibria of utilization and the growth rate are:

$$
\begin{aligned}
& u^{*}=u^{*}\left(z, s_{\pi}, s_{\psi}, \gamma, \pi\right) \\
& g^{*}=g^{*}\left(z, s_{\pi}, s_{\psi}, \gamma, \pi\right)
\end{aligned}
$$

\footnotetext{
${ }^{2}$ This means that we could rewrite equation (1) as $g^{i}=g^{i}\left[\gamma_{w},\left(u-u_{d}\right)\right]$. If profitability did not have any effect on investment, the warranted rate, thus defined, would be equal to $\gamma$.
} 
The partial derivatives of the $u^{*}$ and $g^{*}$ with respect to the saving propensities are negative- the so-called paradox of thrift — and with respect to $\gamma$ is positive, while with respect to $\pi$ it depends on the relative magnitude of the propensities to invest and save out of profits $\left(\partial g^{i} / \partial \pi\right.$ and $\left.\partial g^{s} / \partial \pi\right)$. This is the well-known distinction between wage- and profit-led growth. Finally, the effect of autonomous expenditure is positive.

These results are common in both the Kaleckian and neo-Sraffian framework with two important differences with regard to investment. Following Garegnani (1962), neo-Sraffians do not believe that profitability has an effect on investment decisions; as a result, the economy is always wage-led. Moreover, expectations do not play a role, so that investment is fully induced by income (so that $g^{i}=h \cdot u$ ). These differences are important, but it is beyond the scope of this paper to discuss them. What matters in our discussion is the effect of autonomous expenditure, which is positive.

This conclusion is important because the role of autonomous expenditure, at least in the short and medium run, can be appreciated using any demand-led model (not only Kaleckian but also Kaldorian, Robinsonian, or other); it is not unique in the neo-Sraffian approach. For example, any post-Keynesian economist would say that austerity-a decrease in autonomous government spending-will have a negative effect on the level of economic activity. Consequently, the importance of the SSM type of models is in the analysis of the long run.

\subsection{The Long Run}

The short-run equilibrium rate of capacity utilization is different from the desired rate, which in turn is considered orthogonal to demand (Kurz 1986). The SSM type of models propose a longrun adjustment that brings the utilization rate to its desired level and at the same time maintains what Garegnani (1992) called the "Keynesian hypothesis": the independent determination of investment from saving. The deviation of the rate of utilization from its desired rate has been a constant source of criticism of the Kaleckian model on behalf of Sraffians and others (e.g., Committeri 1986; Auerbach and Skott 1988; Duménil and Lévy 1999; Shaikh 2009; Skott 2010, 
2012), hence the attraction to the supermultiplier mechanism for some Kaleckians (Allain 2015; Lavoie 2016). ${ }^{3}$

Two variables adjust in the long run. One is the autonomous-demand-to-capital ratio (z), which by definition is equal to the growth rate of autonomous demand $(Z)$ minus the accumulation rate.

$$
\hat{z}=\hat{Z}-g^{*}(\cdot ; z)
$$

$Z$ is assumed to grow at a constant rate. Since $\frac{\partial g^{*}}{\partial z}>0$, it follows that $\hat{z}$ converges to zero. In other words, the accumulation rate converges to the exogenous growth rate of autonomous demand. This is the main stabilizing force of the system.

On the other hand, in the canonical SSM model, utilization is brought in line by an adjustment of the propensity to invest $(h)$, which changes in response to deviations of utilization from its desired rate.

$$
\hat{h}=\delta\left(u^{*}-u_{d}\right)
$$

where $\delta$ is a positive constant.

The system of equations (5) and (6) is stable if and only if the adjustment of $h$ is not too fast, and if $\delta$ is sufficiently low (Freitas and Serrano 2015, 12-15).

The neo-Kaleckian variant of the model maintains equation (5), which is true by definition, and complements it with an adjustment of the warranted rate of growth, which changes in response to deviations of the actual growth rate from the warranted growth rate, or equivalently

\footnotetext{
${ }^{3}$ It is worth mentioning that not all Sraffians share the view that in the long run the actual utilization rate needs to be equal to the desired rate. Early discussions of why actual utilization — even on average-deviated from the normal rate in the long run include Garegnani (1992), Vianello (1985), and Ciccone (1986). More recently, some Sraffians have criticized the SSM model on these grounds (Trezzini 1995, 1998; Palumbo and Trezzini 2003).
} 
utilization from its desired rate in response to deviations of actual utilization from its desired rate.

$$
\hat{\gamma}_{w}=\lambda\left(u^{*}-u_{d}\right)
$$

The basic idea of the adjustment mechanisms of equations (6) and (7) is the same. If the actual rate of utilization is higher than the desired rate, accumulation accelerates to bring it in line. Not coincidentally, the stability condition is similar; the adjustment of $\gamma_{w}$ does not have to be too fast; that is, $\lambda$ has to be sufficiently low.

At the long-run equilibrium, the system grows at the rate of growth of autonomous spending. Therefore, only changes in autonomous spending can have permanent growth effects. The paradox of thrift and the paradox of costs are maintained (but as level effects) as the system converges from one fully adjusted position to another.

\section{THE NORMAL RATE OF CAPACITY UTILIZATION IN THE LONG RUN}

As it was explained in the previous section, one of the main attractions of the SSM model is the convergence of the economy toward the normal utilization rate in the long run. This is clear already in Serrano (1995, 85-87) and it is the main reason that neo-Kaleckians have adopted the model, as explained by Allain (2015) and Lavoie (2016, 2017).

There are three reasons why this convergence is important for a long-run model. To begin with, it is not clear why a firm would continue to operate at a level of capacity utilization different from its desired one - the one that maximizes its profits or minimizes its costs - ad infinitum. Second, Kurz (1986) demonstrated that this desired rate of utilization is independent from demand. Finally, data from the Federal Reserve Board (FRB) and other institutions show that the rate of utilization oscillates with the business cycle but is stationary in the medium run.

These arguments have been at the heart of a consistent critique for the Kaleckian model, which was deemed to be a short-run model since it was not able to equate the actual and the desired 
rates of utilization. However, the acceptance that in the long run the economy converges to a supply-determined rate of utilization means that either the role of demand vanishes and the model becomes “classical in the long run” (Duménil and Lévy 1999), or that demand remains independent but distribution becomes endogenous to allow for the convergence (the latter is essentially the neo-Keynesian theory of growth and distribution that was developed by Kaldor [1955] and Robinson [1962]). From that point of view, the SSM model is a significant effort to reconcile the "Keynesian hypothesis” with a classical theory of distribution.

In a relatively recent paper (Nikiforos 2013), which extends Kurz’s model, I have demonstrated that if we take into account scale effects we can show that higher demand leads to a higher rate of capacity utilization for a firm that minimizes its costs. ${ }^{4}$ Moreover, in a companion paper (Nikiforos 2016b), I have shown that the FRB data on capacity utilization are constructed in such a way to capture only business cycle fluctuations and are therefore inappropriate for the examination of the behavior of utilization in the long run. A more appropriate measure of longrun variations of utilization is the average time the capital stock is run during a certain period of time (e.g., how many hours per week — out of the 168 that is maximum-a plant is running). Measured this way, the desired utilization rate is far from stationary. Using these data, I found statistical evidence that demand has an effect on the desired rate of capital utilization.

Therefore, a better way to achieve equality of the actual and the desired rate in the long run is to endogenize the desired rate:

$$
\dot{u}_{d}=\mu\left(u^{*}-u_{d}\right)
$$

where $\mu>0$. Such an adjustment combined with an adjustment of the warranted growth rate as in equation (7) leads to a long-run equilibrium that maintains the short-run results of the model. The growth effects of changes in distribution, the saving rate, or autonomous spending carry

\footnotetext{
${ }^{4}$ This is important because some Kaleckians had argued in favor of an endogenous rate of utilization on the basis that the desired rate of utilization is merely a convention, which changes as the actual rate changes (Lavoie 1995, 1996; Lavoie, Rodríguez, and Seccareccia 2004; Hein, Lavoie, and van Treeck 2012). This is not a convincing justification for the endogeneity of utilization. The choice of the level of utilization is analogous to the choice of the technique of production.
} 
over into the long run. ${ }^{5}$ In that way the long-run state of the economy becomes path dependent; this is a better way to approach the capitalist economy, as opposed to a system that tends to move toward an exogenous and predetermined center of gravity.

By that, I do not mean to say that utilization and the warranted growth rate are the only variables that adjust in the long run. A more complete model of the long run would need to take into account technical change, adjustment in the labor force, buildup and loss of skills, migration, etc. However, endogenizing normal utilization is a better way to build a model for the long run that equalizes actual and normal utilization, and at the same time maintains the "Keynesian hypothesis" and the classical theory of distribution.

A good example of this is the case of Greece. What will be the long-run effects of the extreme austerity of the last nine years? The answer, in my opinion, is that even if austerity eases, the demand shock of the last few years will have a lasting effect on the ability of the Greek economy to grow. To begin with, many Greek firms have shut down and their capital stands idle, while others utilize their productive capacity less than they used to before the crisis. A factory that was running in three shifts before the crisis and is now running just one will not return to the three shifts, even if austerity stops. The one shift is the new normal utilization rate for this factory. Obviously, utilization will not be the only variable that will adjust. A huge "brain drain" is already underway in Greece and it seems reasonable that the loss of more than a quarter of GDP over such a long period of time will also have a negative long-run effect on productivity. Nevertheless, the conclusion remains that a demand shock can have permanent growth effects, even if austerity stops and government expenditure starts growing at its trend rate.

Or, as another example, think of income inequality in the United States. Will the current extreme levels of inequality have long-run growth effects? According to the SSM model, the answer is negative. As long as income distribution remains constant-even at its current levelceteris paribus, the long-run growth rate of the economy will not be affected. In a model where

\footnotetext{
${ }^{5}$ The endogenous adjustment of desired utilization as a long-run adjustment mechanism of the Kaleckian model has been recently proposed by in a note by Dávila-Fernández, Oreiro, and Punzo (2017). However, they propose this as an alternative to the adjustment of the warranted growth rate. Lavoie (2018) has replied with some critical remarks.
} 
desired utilization is endogenous this is not the case; distribution can have long-run growth effects.

\section{A PECULIAR WAY TO THE SECOND KEYNESIAN POSITION}

As Garegnani $(1992,47)$ explains, there have been two main positions on the "Keynesian hypothesis," the "shared hypothesis [is] that in the long period, in which productive capacity changes, no less than in the short period analyzed by Keynes, it is an independently determined level of investment that generates the corresponding amount of savings, rather than an autonomous propensity to save that generates the level of investment as in the traditional answer." ${ }^{6}$ The First Keynesian Position (FKP) proposed endogenous changes in income distribution, which would produce the required savings to match the independent investment decisions. This is what Sen (1963) called the "neo-Keynesian approach" to growth and distribution and is mainly associated with Kaldor (1955) and Robinson (1962). Sen calls the model neo-Keynesian as opposed to Keynesian because of the rather un-Keynesian assumption of full employment (Kaldor) or full utilization of capital (Robinson). According to the Second Keynesian Position (SKP) "investment can generate the corresponding amount of savings by raising the level of output together with the corresponding productive capacity without any need to change the real wage and the normal rate of profits” (Garegnani 1992, 47). In other words, the SKP is able to combine the principle of effective demand with the classical theory of distribution because it drops the assumption of full employment/utilization that Kaldor and Robinson made.

In its turn, the SSM model is able to square the circle, and combine the SKP with normal utilization. However, this is achieved in a peculiar way and comes at a cost: investment becomes quasi-endogenous. Although the rate of accumulation is independent from savings, it has to fully adjust to the exogenous growth rate of autonomous expenditure. Investment does not matter, because by assumption investment has to adjust in order to bring the actual utilization to its exogenous normal level (equations [6] and [7], above). In other words, none of the arguments

\footnotetext{
${ }^{6}$ The term “Keynesian hypothesis” was coined by Kaldor $(1955,95)$.
} 
of the investment function play any role whatsoever in the long run. This is strangely reminiscent of supply-side models or the FKP where the accumulation rate converges to the exogenous natural growth rate in the long run. The role of the natural growth rate is played here by the growth rate of autonomous expenditure. This is probably consistent with the letter but certainly not the spirit of the SKP and the Keynesian hypothesis. This is the theoretical reason behind the aforementioned implausible predictions of the SSM model for the long-run effectsor their lack thereof—of austerity in Greece or distribution in the United States.

As I argued in previous section, a better way to maintain the Keynesian hypothesis, the classical theory of distribution, and achieve a fully adjusted position in the long run is by endogenizing the normal rate of utilization. In this way the economy becomes path-dependent and does not tend to revert toward any sort of endogenously determined, "natural" growth rates. This view is more consistent with the ideas of classical political economists and Keynes on the dynamics of capitalism.

\section{HOW AUTONOMOUS IS “AUTONOMOUS DEMAND” FROM A STOCK-FLOW CONSISTENT (SFC) POINT OF VIEW?}

At the end of section 3, I argued that the Greek austerity of the last decade will most probably have long-run negative effects on the ability of the economy to grow (through an endogenous adjustment of the normal utilization rate, the warranted rate of growth, productivity effects, etc.), even if the exogenous decrease in fiscal spending is reversed and government expenditure returns to its trend rate of growth. A careful reader with some basic knowledge of Greece's political economy will object to the previous argument: government expenditure will not return autonomously to its precrisis growth rate. According to the agreements with the troika, the Greek government has to achieve primary surpluses of 3.5 percent every year (in order for government debt to become sustainable), so government expenditure will increase only if GDP growth creates enough fiscal space. In other words, government expenditure is not autonomous but is dependent on GDP. 
This brings us to a deeper problem with the SSM approach: How autonomous is the so-called autonomous demand? The problem is more general than government expenditure in Greece. To the extent that the government budget is determined with some reference to the fiscal deficit and potential tax revenues, government expenditure is not autonomous. I think that everyone would agree that this is how government budgets are drafted most of the time.

The same is true with any debt-financed expenditure. Within the SSM approach, any noncapacity debt-financed expenditure is treated as autonomous. However, it is hard to see how this kind of expenditure is really autonomous from economic variables in the long run. Take, for example, residential investment, which is another major component of autonomous expenditure within the SSM theory. Do households make their residential investment decisions without any reference to their (expected lifecycle) income? This is a strange assumption to make, especially for a theory that at the same time rejects the role of uncertainty, expectations, and animal spirits in investment decisions as “too subjective and nebulous” (Cesaratto 2017, 7). ${ }^{7}$

The points so far in this section about the nonautonomy of demand in the long run have been made by Skott (2017: section 3). ${ }^{8}$ However, there is a more fundamental, albeit subtle, reason why debt-financed expenditure cannot be autonomous in the long run. Stock-flow consistency implies that debt-financed "autonomous" expenditure increases the stock of liabilities of the related sector. As mentioned above, in the long-run equilibrium of the canonical SSM model, autonomous expenditure and income grow at the same rate, which implies that the debt-toincome ratio remains stable. ${ }^{9}$

Assume that we start from an equilibrium like that and then for a certain period of time the debtto-income ratio rises. This can happen either due to an acceleration of debt-financed autonomous expenditure without an equiproportionate acceleration of income, or due to a negative shock to income while the growth rate of autonomous expenditure remains constant.

\footnotetext{
${ }^{7}$ This theory of investment goes back to Garegnani (1962, 1978, 1979).

${ }^{8}$ It is also worth mentioning that the first one to express doubts about "a hard-and-fast line between induced and autonomous investment” was Harrod $(1959,461)$ with reference to the original supermultiplier model of Hicks (1950). Harrod's concern was to what extent the presence of autonomous investment invalidated his "instability principle.” He argues that certain components of investment that are exogenous in some phases of the cycle might be revised in some other phases.

${ }^{9}$ See Pariboni (2016) for a more detailed discussion.
} 
Over this period of time, the system moves, to use the Minskyan terminology, from a hedge, to a speculative, and eventually a Ponzi position.

How will the system adjust? The SSM theory implies that somehow there is going to be an acceleration of growth that will stabilize the debt-to-income ratio. Reality - and the related theory of financial crises (Minsky 1975, 1986; Kindleberger and Aliber 2011)—is different. At a certain point after the system enters the Ponzi phase, debt-financed expenditure slows down because the agents with fragile balance sheets will increase their saving and/or the banking sector will stop being willing to provide more loans. Thus, autonomous expenditure stops being autonomous. Then the crisis follows. The decrease in expenditure reduces output and further increases the debt-to-income ratio, which then induces a further decrease in (non-)autonomous expenditure, and the cycle continues. This debt-deleveraging cycle is characteristic of any financial crisis. $^{10}$

If government is not the sector that has increased its debt-to-income ratio, the usual reaction in a situation like this is countercyclical fiscal (and monetary) policy. If it is the sector with the high debt-to-income ratio, a likely reaction is austerity in order to reduce it. In both cases, government expenditure is also, to a large extent, reacting to changes in income, and therefore is also not autonomous. ${ }^{11}$

The last three decades are awash with these kinds of processes all around the world. We can think, for example, about the process that led to the recent crisis in the United States. The household sector increased its debt-financed consumption and residential investment. This increase contributed to the growth of the economy for a certain period of time, however at the same time it led to the increase in the debt-to-income ratio of households. This increase

\footnotetext{
${ }^{10}$ Obviously, a big part of all the phases of a cycle like that involves changes in product and asset prices; these changes further magnify the elasticity of expenditure to the state of the economy.

${ }^{11}$ The ability of the government to increase its debt is obviously much greater than that of the private sector. However, from an SFC point of view, assuming that autonomous government expenditure in itself can be the longrun driving force of the economy means that public deficits and public debt are accepted politically and do not matter economically (Godley and Lavoie 2007b).
} 
eventually led to an increase in the savings rate of the household sector, which triggered the slowdown and the crisis. ${ }^{12}$

This is the deeper reason why debt-financed expenditure cannot be autonomous in the long run and why income and other economic variable have influence on all expenditure decisions. In the long run, expenditure decisions become endogenous in order to stabilize the debt-to-income ratios. This endogeneity of expenditures is also responsible for the stationarity of the shares of the various "induced" and "autonomous" expenditures in GDP, which sometimes is interpreted as a verification of the SSM story. That is why it seems absurd that households make their residential investment decisions without any reference to their income. Such a behavior would imply that changes in their debt-to-income ratio would not matter for them.

The above also means that, because of the assumption of the autonomy of expenditures, the SSM model is inherently unable to be used for the analysis of debt and financial crises in any meaningful way. Any analysis of financial crises requires the endogeneity of "autonomous" debt-financed expenditure. However, this endogeneity cancels the whole supermultiplier approach: the SSM model remains like a train without its locomotive.

The argument is more general than cases of autonomous expenditures that are debt financed, because any kind of autonomous expenditure will, in principle, lead to changes in the netfinancial-assets-to-income ratio of the related sector. For example, it is true that capitalists and rentiers can increase their consumption for a certain period without reference to income and without accumulating liabilities, presumably because they have a stock of wealth to fall back onto. Nevertheless, long-run autonomy of their expenditure implies that they ignore the effects their consumption decisions have on their balance sheets, which is not the case.

What about exports? If a country experiences a negative export shock, then we are in a situation of continuous accumulation of net foreign liabilities, which eventually will trigger an endogenous adjustment. In the case of an export boom the constraints are less strict. However, such a situation implies that the country under examination will be willing to pursue a

\footnotetext{
${ }^{12}$ The savings rate of the household sector started increasing in 2006. This was the trigger of the crisis that followed.
} 
continuous increase in its net financial position abroad and the related capital outflows. Among others, Garegnani (1962; 2015, 15-20) argued that this is not likely. If this is right, then these kinds of autonomous expenditures will sooner or later adjust endogenously. Moreover, the view that a country can keep increasing its net foreign asset position without a problem implies the assumption of a small, open economy, which can be analyzed without reference to the feedback effects its behavior might have. This is not a good assumption for many economies like the United States, the Eurozone, Germany, China, India, or Japan. Godley and Lavoie (2007a, 17071) motivate the use of open economy SFC models on these grounds. For example, the growth of the German economy has been driven by trade surpluses. However, the implications of these surpluses for the balance sheets of Germany's trading partners will eventually trigger a correction.

Three final comments are in order here. First, I do not mean to say that any model that converges to stable debt-income ratios is problematic. It is common within the so-called SFC literature that models converge to stable debt-income ratios; most models in Godley and Lavoie (2007a) do that. The difference is that the SFC approach does not rest on the assumption of exogeneity of a certain part of demand. At a basic level, this kind of equilibrium in a stable SFC model serves as a benchmark for evaluating real-world developments. For example, Godley (1999) reached his conclusion about the unsustainability of the growth process in the United States in the 1990s by observing the increasing debt-to-income ratio of the private sector, and contrasting it with a sustainable, stable ratio. At a next level, these models serve as a base for building more realistic models of financial cycles and crises. ${ }^{13}$ The problem with the SSM model is that it cannot make this last step. Endogenizing debt-financed expenditure poses a fundamental contradiction for the model.

Second, I also do not mean to say that any model with autonomous expenditure is not useful. It is often very useful to resort to this kind of abstraction when we think about short- or mediumrun issues. To put it differently, treating certain components of demand as autonomous is a closure choice that might be useful for the analysis of certain short- or medium-run situations, but certainly not for the long run. For example, a useful way to think about the reasons behind

\footnotetext{
${ }^{13}$ For a recent survey of the SFC modeling principles and literature, see Nikiforos and Zezza (2017). Minskyan models of financial cycles and crises are discussed in section 3 of that paper.
} 
the increase in the debt-to-income ratio of the households at the bottom of the distribution in the United States is that in the face of stagnating incomes these households increased their indebtedness to maintain their living standards. In other words, for a period of time the consumption of these households was quasi-autonomous. ${ }^{14}$ However, this is a short-run story, which can be approached with a variety of models. As it was explained in section 2, the SSM theory is fundamentally a long-run one. Over that time horizon, the assumption of autonomy is neither realistic nor useful. ${ }^{15}$

Finally, if the data-generating processes for the debt-financed expenditures are not autonomous, the empirical validation of the SSM story becomes problematic. Like in the theoretical model, recent empirical contributions to the related literature (e.g., Girardi and Pariboni 2016, 2017) assume that components of demand-like government expenditure and residential investmentare autonomous. For the reasons explained here, it is really hard to think that these components of demand are not influenced by the trajectory of income or other economic variables.

\section{CONCLUSION}

The present paper provided a critical discussion of the Sraffian supermultiplier model. I explained that the SSM model is a model of the long run; in the short run the model does not provide any novel intuition compared to a standard Keynesian/Kaleckian model. Therefore, we need to assess the advantages and the disadvantages of the model with respect to that time horizon.

Probably the main attraction of the model is that it can combine a long-run autonomous role for demand together with a classical theory of distribution and convergence toward an exogenous-

\footnotetext{
${ }^{14}$ For an analysis of the increase of the indebtedness of the households at the bottom of the distribution in the United States before the crisis along these lines, see Nikiforos (2016a).

${ }^{15}$ In a recent paper, which they explicitly locate within the SSM approach, Fiebiger and Lavoie (2017) argue that debt-financed household semi-autonomous expenditure contributed to the growth of the US economy before the crisis and the lack of it explains the slow recovery that has followed (the prefix "semi" makes a world of difference here). I am in agreement with their argument, but I disagree that it provides support to the SSM approach. As argued here, semi-autonomous expenditure can be a useful analytical concept in general, but it is not satisfactory in the case of the SSM model because of its long-run nature.
} 
to-demand normal degree of capacity utilization. I argued that there are good theoretical and empirical reasons to believe that the rate of capacity utilization is endogenous to demand in the long run. A model of a fully adjusted position should then endogenize the normal rate of utilization. Such a model can produce not only level effects, like the SSM model does, but also growth effects. Moreover, the combination of this trinity (demand, classical distribution, and exogenous utilization) comes at the cost of a quasi-endogenous investment. In the medium and long run, investment has a passive role and the rate of accumulation simply adjusts to the growth rate of autonomous demand.

Finally, there are several reasons to be skeptical about the autonomy of the so-called autonomous expenditure in the long run. From an SFC point of view this kind of autonomy presupposes either that there are no episodes of increasing liabilities-to-income ratios, or that if there are there will be an endogenous acceleration of accumulation that will stabilize the ratios. In any case, the model cannot allow for a financial crisis. The experience of the last decades, and the related theory of financial crises, suggests that a period of increase in the debt-to-income ratios will be followed by an endogenous adjustment of the (previously autonomous) expenditure decisions by the agents of the sectors with fragile balance sheets. Therefore, autonomous expenditure is not really autonomous in the long run. This is a fundamental theoretical problem for the SSM approach. 


\section{REFERENCES}

Allain, Olivier. 2015. "Tackling the instability of growth: a Kaleckian-Harrodian model with an autonomous expenditure component.” Cambridge Journal of Economics 39(5): 135171.

Auerbach, Paul, and Peter Skott. 1988. “Concentration, Competition and Distribution-A Critique of Theories of Monopoly Capital.” International Review of Applied Economics 2(1): 42-61.

Bortis, Heinrich. 1997. Institutions, behaviour and economic theory: a contribution to classical Keynesian political economy. Cambridge, UK: Cambridge University Press.

Cesaratto, Sergio. 2015. “Neo-Kaleckian and Sraffian controversies on the theory of accumulation.” Review of Political Economy 27(2): 154-82.

— 2017. "Garegnani, Ackley and the years of high theory at Svimez.” Centro Sraffa Working Papers no. 26. Rome: Centro Sraffa.

Cesaratto, Sergio, Franklin Serrano, and Antonella Stirati. 2003. “Technical change, effective demand and employment.” Review of Political Economy 15(1): 33-52.

Ciccone, Roberto. 1986. "Accumulation and capacity utilization: some critical considerations on Joan Robinson’s theory of distribution.” Political Economy 2(1): 17-36.

Committeri, Marco. 1986. "Some comments on recent contributions on capital accumulation.” Political Economy 2(2): 161-86.

Dávila-Fernández, Marwil J., Jose L. Oreiro, and Lionello F. Punzo. 2017. “Inconsistency and over-determination in neo-Kaleckian growth models: A note.” Metroeconomica. Online first, doi: https://doi.org/10.1111/meca

Duménil, Gérard, and Dominique Lévy. 1999. "Being Keynesian in the Short Term and Classical in the Long Term: The Traverse to Classical Long-Term Equilibrium.” The Manchester School 67(6): 684-716.

Fazzari, Steven M., Pietro E. Ferri, and Anna Maria Variato. 2018. "Demand-led growth and accommodating supply.” Unpublished manuscript.

Fazzari, Steven M., Pietro E. Ferri, Edward G Greenberg, and Anna Maria Variato. 2013. “Aggregate demand, instability, and growth.” Review of Keynesian Economics 1(1): 121.

Fiebiger, Brett, and Marc Lavoie. 2017. “Trend and business cycles with external markets: Noncapacity generating semi-autonomous expenditures and effective demand.”

Metroeconomica. Online first, doi: https://doi.org/10.1111/meca.12192 
Freitas, Fabio, and Franklin Serrano. 2015. "Growth rate and level effects, the stability of the adjustment of capacity to demand and the Sraffian supermultiplier." Review of Political Economy 27(3): 258-81.

Garegnani, Pierangelo. 1962. “Il problema della domanda effettiva nello sviluppo economico italiano.” Report. Rome: Svimez Institute.

- 1979. "Notes on consumption, investment and effective demand: I." Cambridge Journal of Economics 2(4): 335-53.

- 1979. "Notes on consumption, investment and effective demand: II.” Cambridge Journal of Economics 3(1): 63-82.

—. 1992. "Some Notes for an Analysis of Accumulation.” In Joseph Halevi, David Laibman, and Edward J. Nell (eds.), Beyond the steady state: a revival of growth theory. New York: St. Martin’s Press.

— 2015. “The problem of effective demand in Italian economic development: On the factors that determine the volume of investment." Review of Political Economy 27(2): 111-33.

Girardi, Daniele, and Riccardo Pariboni. 2016. "Long-run Effective Demand in the US Economy: An Empirical Test of the Sraffian Supermultiplier Model.” Review of Political Economy 28(4): 523-44.

—_. 2017. “Autonomous Demand and the Investment Share.” Unpublished manuscript.

Godley, Wynne. 1999. Seven Unsustainable Processes: Medium-term Prospects and Policies for the United States and the World. Strategic Analysis. Annandale-on-Hudson, NY: Levy Economics Institute of Bard College. January.

Godley, Wynne, and Marc Lavoie. 2007a. Monetary Economics: An Integrated Approach to Credit, Money, Income, Production and Wealth. London: Palgrave MacMillan.

- 2007b. "Fiscal policy in a stock-flow consistent (SFC) model.” Journal of Post Keynesian Economics 30(1): 79-100.

Harrod, Roy F. 1959. “Domar and dynamic economics.” The Economic Journal 69(275): 45164.

Hein, Eckhard, Marc Lavoie, and Till van Treeck. 2012. "Harrodian instability and the 'normal rate' of capacity utilisation in Kaleckian models of distribution and growth-a survey.” Metroeconomica 63(1): 139-69.

Hicks, John R. 1950. A Contribution to the Theory of the Trade Cycle. Oxford: Clarendon Press. 
de-Juan, Oscar. 2005. "Paths of accumulation and growth: towards a Keynesian long-period theory of output.” Review of Political Economy 17(2): 231-52.

Kaldor, Nicholas. 1955. “Alternative Theories of Distribution.” The Review of Economic Studies 23(2): 83-100.

Kindleberger, Charles P., and Robert Z. Aliber. 2011. Manias, Panics and Crashes: A History of Financial Crises, sixth edition. New York: Palgrave Macmillan.

Kurz, Heinz. 1986. “Normal positions and capital utilisation.” Political Economy 2(1): 37- 54.

Lavoie, Marc. 1995. "The Kaleckian Model of growth and distribution and its neo-Ricardian and neo-Marxian critiques.” Cambridge Journal of Economics 19(6): 789-818.

- 1996. "Traverse, Hysteresis and Normal Growth Rates of Capacity Utilization in Kaleckian Models of Growth and Distribution.” Review of Radical Political Economy 28(4): 113-47.

- 2016. "Convergence towards the normal rate of capacity utilization in neo-Kaleckian Models: The Role of Non-Capacity Creating Autonomous Expenditures.” Metroeconomica 67(1): 172-201.

- 2017. "Prototypes, reality and the growth rate of autonomous consumption expenditures: a rejoinder.” Metroeconomica 68(1): 194-99.

—. 2018. "Inconsistencies in the note of Dávila-Fernández, Oreiro and Punzo.” Metroeconomica. Online first, doi: https://doi.org/10.1111/meca.12202

Lavoie, Marc, Gabriel Rodríguez, and Mario Seccareccia. 2004. "Similitudes and Discrepancies in Post-Keynesian and Marxist Theories of Investment: A Theoretical and Empirical Investigation.” International Review of Applied Economics 18(2): 127-49.

Minsky, Hyman. 1975. John Maynard Keynes. New York: Columbia University Press.

—. 1986. Stabilizing an Unstable Economy. New Haven, CT: Yale University Press.

Nikiforos, Michalis. 2013. "The (Normal) rate of capacity utilization at the firm level.” Metroeconomica 64 (3): 513-38.

_ 2016a. "A nonbehavioral theory of saving." Journal of Post Keynesian Economics 39(4): 562-92.

- 2016b. "On the 'utilisation controversy': a theoretical and empirical discussion of the Kaleckian model of growth and distribution." Cambridge Journal of Economics 40(2): 437-67. 
Nikiforos, Michalis, and Gennaro Zezza. 2017. "Stock-flow Consistent Macroeconomic Models: A Survey.” Journal of Economic Surveys 31(5): 1204-39.

Palumbo, Antonella, and Attilio Trezzini. 2003. "Growth without normal capacity utilization.” European Journal of the History of Economic Thought 10(1): 109-35.

Pariboni, Riccardo. 2016. "Household consumer debt, endogenous money and growth: A supermultiplier-based analysis.” PSL Quarterly Review 69(278): 211-33.

Robinson, Joan. 1962. Essays in the Theory of Economic Growth. London: The MacMillan Press.

Sen, Amartya K. 1963. “Neo-Classical and Neo-Keynesian Theories of Distribution.” Economic Record 39(85): 53-64.

Serrano, Franklin. 1995. "Long period effective demand and the Sraffian supermultiplier." Contributions to Political Economy 14(1): 67-90.

Serrano, Franklin, Fabio Freitas, and Gustavo Bhering. 2017. “The Trouble with Harrod: the fundamental instability of the warranted rate in the light of the Sraffian

Supermultiplier.” Grupo de Economia Política do Instituto de Economia Discussion Paper 018-2017. Rio de Janeiro: Federal University of Rio de Janeiro.

Shaikh, Anwar. 2009. "Economic policy in a growth context: a classical synthesis of Keynes and Harrod.” Metroeconomica 60(3): 455-94.

Skott, Peter. 2010. “Growth, Instability and Cycles: Harrodian and Kaleckian Models of Accumulation and Income Distribution.” In Mark Setterfield (ed.), Handbook of Alternative Theories of Economic Growth. London: Edward Elgar.

— 2012. "Theoretical and empirical shortcomings of the Kaleckian investment function.” Special Issue on Kaleckian Growth Theory, Metroeconomica 63(1): 109-38.

—. 2017. "Autonomous demand, Harrodian instability and the supply side.” Metroeconomica. Online first; doi: https://doi.org/10.1111/meca.12181

Trezzini, Attilio. 1995. "Capacity utilisation in the long run and the autonomous components of aggregate demand.” Contributions to Political Economy 14(1): 33-66.

— 1998. "Capacity utilisation in the long run: some further considerations." Contributions to Political Economy 17(1): 53-67.

Vianello, Fernando. 1985. “The pace of accumulation.” Political Economy 1(1): 69-87. 